\title{
Correlation of severity of hyperandrogenism with ovarian stroma to area ratio and stromal echogenicity in polycystic ovary syndrome patients
}

\author{
Pooja Gupta*, Harsha Gaikwad
}

Department of Obstetrics \& Gynaecology, Vardhman Mahavir Medical College \& Safdarjung Hospital, New Delhi, India

Received: 29 October 2015

Accepted: 12 December 2015

*Correspondence:

Dr. Pooja Gupta,

E-mail: drpoojagupta1@gmail.com

Copyright: (c) the author(s), publisher and licensee Medip Academy. This is an open-access article distributed under the terms of the Creative Commons Attribution Non-Commercial License, which permits unrestricted non-commercial use, distribution, and reproduction in any medium, provided the original work is properly cited.

\begin{abstract}
Background: Polycystic ovary syndrome is one of the most common endocrine disorders of reproductive age group. Rotterdam consensus although includes ovarian volume in diagnosis of PCOS but its ovarian stroma area that corresponds histological and thus its clinical features.

Methods: A prospective study conducted on 55 PCOS cases and 55 age and weight matched healthy volunteers. Detailed medical, menstrual history and examination for clinical hyperandrogenism and anthropometry was done. Fasting venous blood samples were obtained on day 2 for androgen profiles. All the patients were subjected to pelvic ultrasound and also a 3D ultrasound was done. The S/A (ovarian stroma to area ratio) were obtained by outlining the peripheral profile of the stroma with a caliper and similarly total ovarian area by outlining in the maximum plane section. Stromal echogenicity was assessed semi quantatively.

Results: S/A exhibits positive and significant correlation with DHEAS $(r=0.565, \mathrm{p}<0.05)$, testosterone $(r=0.272$, $\mathrm{p}<0.05)$ and negative but insignificant correlation with hirsuitism score with $(r=-0.07, p>0.05)$ in cases, whereas stoma echogenicity was increased in $78.2 \%$ cases and $20 \%$ controls and correlated significantly with DHEAS levels and not $\mathrm{H}$ score, probably due to small sample size.

Conclusions: S/A bears a positive significant correlation with androgenic parameters studied and can be considered as one of the best predictor of hyperandrogenism. The stroma echogenicity measured semiquantatively can act as a clue for PCOS diagnosis. Their measurement and follow up during course of treatment may show significant role in defining the severity, progression or regression of the disease.
\end{abstract}

Keywords: Hyperandrogenism, Stroma echogenicity, Ovarian stroma, S/A ratio

\section{INTRODUCTION}

Polycystic ovary syndrome is one of the most common endocrine disorders of the reproductive age group .This syndrome was first described by I.F. Stein and M.L. Leventhal in 1935 so often called as Stein and Leventhal Syndrome. ${ }^{1}$ It has a reported prevalence of $20 \%$ using Rotterdam criteria. ${ }^{2}$ Hyperandrogenism is the hallmark of PCOS and originates predominantly from ovarian theca interstitial cells, which are characterized by increased capacity for androgen biosynthesis. ${ }^{2-4}$ Elevated circulating androgen levels are seen in $60-80 \%$ patients, while hirsuitism in $60 \%$ and acne in $15 \%$. This represents an independent risk factor for the development of hypertension and cardiovascular morbidity and metabolic syndrome. ${ }^{5}$ Androgen excess also leads to decrease in insulin sensitivity and glucose tolerance. Hyperandrogenemia if left untreated may lead to 
pathogenesis of acne vulgaris and also psychological sequel. Elevated androgen levels represent an independent risk factor for the development of hypertension and cardiovascular complications. ${ }^{4}$

Concerning ultrasound as diagnostic criteria, these have progressively changed evolving from simple evaluation of ovarian volume to identification of a typical follicular pattern lastly to modification of ovarian stroma. ${ }^{6}$ Increased echogenicity of stroma corresponds to histological findings of theca cell hyperplasia. Proportion between stroma and ovary surface in median surface has been indicated as a reliable marker for hyperandrogenism and correlates with ovarian androgenic dysfunction. ${ }^{7}$

There exists sufficient evidence that supports positive correlation between ultrasound features and biochemical indices of PCOS suggesting that ultrasound can play role in predicting prognosis and severity. ${ }^{7}$

\section{METHODS}

This was a prospective study conducted on PCOS and an equal number of ages and weight matched healthy volunteers from September 2012 to December 2014. Patients were interviewed for medical and menstrual history and examined for clinical hyperandrogenism and anthropometry. Fasting venous blood samples were obtained on day 2 of cycle for androgen profiles on all patients. A routine pelvis ultrasound was done on all patients and also a 3D ultrasound was done to evaluate stroma echogenicity semi quantatively.

The cases were diagnosed as PCOS according to Rotterdam Criteria when any two of the following features were present; clinical or biochemical hyperandrogenemia, menstrual complaints like Oligomenorrhea or amenorrhea and polycystic ovaries on ultrasound (presence of 12 or more follicles of $2-8 \mathrm{~mm}$ or ovarian volume greater than $10 \mathrm{ml}$ ).

The control group consisted of age and weight matched healthy individuals without PCOS. Health of control group was determined on basis of medical history, general physical and pelvic ultrasound. Known smokers, alcoholics, medical disorders, history of unilateral ovarian resection, intake of medication (contraceptives, anti-androgens, insulin sensitizers) in past 6 months, those with single dominant follicle on ultrasonography were excluded from the study.

From all participants detailed history was taken of menstrual and reproductive function and other complaints like weight gain, galactorrhoea and thyroid dysfunction. Examination was carried noting anthropometry and BMI. Hirsuitism was evaluated by modified Ferriman Gallaway score which scores the body distribution of hair at 9 sites, each site giving a score of 4 . Score ranges from 0 -36. A score of more than 6 indicates hirsuitism.
Serum levels of following hormonal parameters were obtained after an overnight fasting of 12 hours in the early follicular phase of patients between 8 am to $10 \mathrm{am}$; $\mathrm{FSH}, \mathrm{LH}$, total testosterone, prolactin, estradiol and DHEAS. Meanwhile transabdominal ultrasound with 3.5 - $5 \mathrm{MHz}$ three dimensional probes was carried out in right ovary as data from left ovary appeared less homogeneous, possibly in relation to rectal ampulla.

The S/A ratio was obtained by outlining the peripheral profile of stroma with a caliper and total ovarian area by outlining the external limits of the ovary in median section.

Stroma echogenicity is represented in a semi quantitative manner as score 1 (normal), score 2 (moderately increased), and score 3 (frankly increased) with respect to myometrium.

\section{RESULTS}

The mean weight of cases was $56.78 \pm 9.35 \mathrm{Kg}$ and of controls was $51.09 \pm 3.85 \mathrm{Kg}$. The difference was statistically significant between the groups $(p<0.05)$. The mean height of cases was $150.56 \pm 13.40 \mathrm{~cm}$ and of controls was $152.55 \pm 3.31 \mathrm{~cm}$. The difference was not statistically significant $(\mathrm{p}=0.723)$. Body Mass Index (BMI) was calculated by dividing the weight in kilograms to square of height in meters. The mean BMI of cases was $24.09 \pm 4.03 \mathrm{Kg} / \mathrm{m}^{2}$ and of controls was $21.95 \pm 1.67$ $\mathrm{Kg} / \mathrm{m}^{2}$.The difference was statistically significant with $\mathrm{p}<0.05$ (Table 1).

Table 1: Comparison of body mass index (BMI).

\begin{tabular}{|lllll|}
\hline \multirow{2}{*}{ Group } & \multicolumn{3}{c|}{ BMI in $\mathrm{Kg} / \mathrm{m}^{2}$} \\
Cases & BMI $<25$ & BMI $\geq 25$ & Total \\
\hline \multirow{2}{*}{ Controls } & $\begin{array}{l}\text { Count } \\
\text { \% within } \\
\text { group }\end{array}$ & $65 \%$ & $35 \%$ & $100 \%$ \\
\cline { 2 - 5 } & $\begin{array}{l}\text { Count } \\
\text { \% within } \\
\text { group }\end{array}$ & 53 & 2 & 55 \\
\hline$\left(25 \mathrm{~kg} / \mathrm{m}^{2}=\right.$ overweight $)$ & & $3.6 \%$ & $100 \%$ \\
\hline
\end{tabular}

Clinical hyperandrogenism was evaluated by hirsuitism (H) score or Ferriman Gallaway score evaluated at 9 sites in body and each given a score of 4 . Out of 110 patients, 46 cases $(83.6 \%)$ and 32 controls $(58.2 \%)$ had $\mathrm{H}$ score $>6$ whereas 9 cases $(16.4 \%)$ and 23 controls $(41.8 \%)$ had $\mathrm{H}$ score $>6$. Further mean values of hirsuitism score distributed between cases and controls are depicted (Table 2).

Table 2: Comparison of hirsuitism $(\mathrm{H})$ score.

\begin{tabular}{|l|ll|}
\hline Group & Mean & Standard deviation \\
\hline Cases & 9.62 & 2.62 \\
\hline Controls & 5.90 & 2.81 \\
\hline
\end{tabular}


Biochemical androgen levels were assessed by day 2 fasting venous samples involving DHEAS and total testosterone. The mean value of testosterone in cases was $1.73 \pm 0.72 \mathrm{ng} / \mathrm{ml}$ and $1.52 \pm 1.50 \mathrm{ng} / \mathrm{ml}$ in controls. The difference in the mean value was statistically significant whereas mean value of DHEAS in cases was $2.21 \pm 0.79$ $\mathrm{ng} / \mathrm{ml}$ controls was $1.51 \pm 0.76 \mathrm{ng} / \mathrm{ml}$. The difference in the mean values was also found to be statistically significant.

The mean total ovarian area measured by caliper method in cut section on ultrasound was identified as $6.96 \pm 1.52$ $\mathrm{cm}^{2}$ in cases and $6.69 \pm 0.59 \mathrm{~cm}^{2}$ in controls. This difference was not statistically significant $(p>0.05)$. The mean value of ovarian stroma area in cases is $1.91 \pm 0.51 \mathrm{~cm}^{2}$ and $1.44 \pm 0.59 \mathrm{~cm}^{2}$.The difference between the mean values was statistically significant $(\mathrm{p}<0.05)$. The mean value of ovarian stroma to area ratio (S/A) is $0.28 \pm 0.05$ in cases and $0.20 \pm 0.05$ in controls.
This difference of means was statistically significant with $\mathrm{p}<0.05$ (Table 3).

Table 3: Comparison of mean value of ovarian stromal area and ovarian total area.

\begin{tabular}{|llll|}
\hline & $\begin{array}{l}\text { Ovarian } \\
\text { stromal area } \\
\left(\mathrm{cm}^{2}\right)\end{array}$ & $\begin{array}{l}\text { Ovarian } \\
\text { total area } \\
\left(\mathrm{cm}^{2}\right)\end{array}$ & $\begin{array}{l}\text { Ovarian } \\
\text { stromal to area } \\
\text { ratio }(\mathbf{S} / \mathbf{A})\end{array}$ \\
\hline Cases & $1.91 \pm 0.51$ & $6.96 \pm 1.52$ & $0.28 \pm 0.05$ \\
\hline Controls & $1.44 \pm 0.59$ & $6.69 \pm 1.01$ & $0.20 \pm 0.05$ \\
\hline
\end{tabular}

The stromal echogenicity index was scored as 1 (normal), 2 (moderately increased) and 3 (frankly increased) with respect to myometrium. Out of 110 patients, 12 cases (21.8\%) and 44 controls $(80 \%)$ had normal stromal echogenicity whereas 25 cases $(45.4 \%)$ and 9 controls $(16.4 \%)$ had moderately increased. Further it was observed that 18 cases $(32.8 \%)$ and 2 controls (3.6\%) had frankly increased stromal echogenicity (Table 4).

Table 4: Comparison of stromal echogenicity.

\begin{tabular}{|c|c|c|c|c|}
\hline \multirow[b]{3}{*}{ Cases } & & Score $=1$ (Normal) & Score $=\mathbf{2}$ (Moderately increased) & Score=3 (Frankly increased) \\
\hline & Count & 12 & 25 & 18 \\
\hline & $\%$ within group & $21.8 \%$ & $45.4 \%$ & $32.8 \%$ \\
\hline \multirow[b]{2}{*}{ Controls } & Count & 44 & 9 & 2 \\
\hline & $\%$ within group & $80 \%$ & $16.4 \%$ & $3.6 \%$ \\
\hline
\end{tabular}

Using correlation studies employing Pearson formula, it was observed that testosterone levels were positively correlated with ovarian stroma to area ratio in cases and which was statistically significant $(\mathrm{r}=0.272, \mathrm{p}=0.044)$. Similarly DHEAS levels increased with increase in ovarian stroma to area ratio and were statistically highly significant $(\mathrm{r}=0.565, \mathrm{p}=0.000002)$. There was decrease in $\mathrm{H}$ score with increase in values of ovarian stroma to area ratio which was not statistically significant ( $r=-0.07, p>0.05)$ among cases (Table 5).

Table 5: Correlation of clinical and biochemical hyperandrogenism with ovarian stroma to area ratio.

\begin{tabular}{|lllll|}
\hline & Cases & \multicolumn{3}{c|}{ Controls } \\
\hline Testosterone & $\mathrm{r}$ & $\mathrm{p}$ & $\mathrm{r}$ & $\mathrm{p}$ \\
\hline DHEAS & 0.272 & 0.044 & 0.175 & 0.200 \\
\hline Hirsuitism score & 0.565 & 0.000 & 0.017 & 0.902 \\
\hline
\end{tabular}

( $r=$ correlation coefficient; $-=$ negative correlation; $\mathrm{p}<0.05$ significant).

The increase in testosterone with increase in the values of ovarian stroma to area ratio was not significant $(r=0.175$, $\mathrm{p}>0.05$ ). The increase in DHEAS level with increase in values of ovarian stroma to area ratio was not significant $(\mathrm{r}=0.017, \mathrm{p}>0.05)$ among controls. There was decrease in values of $\mathrm{H}$ score with increase in values of ovarian stroma to area ratio which was not statistically significant $(r=-0.10, p>0.05)$.

\section{DISCUSSION}

Nutritional status on health is issue of concern in the present world. Obesity and excess weight and predisposes to androgen excess, hirsuitism, infertility and pregnancy complications both independently and exacerbating PCOS. Body Mass Index (BMI) derived from height (in meters) and weight (in kilograms) is a novel marker for nutritional status. Global cut offs points as overweight has been set by WHO as >25.In this study $35 \%$ of cases and $3.6 \%$ of control population had BMI $>25$. Women with PCOS are generally obese, however in the present study $65 \%$ of cases had normal BMI. This suggests that there exist a good number of lean PCOS patients in the society. Our study demonstrated statistically significant distribution of BMI between the two groups $(\mathrm{p}=0.006)$ and this was consistent with the findings of Lam $\mathrm{P}$ et al and Loverro G. ${ }^{8,9}$

Ovarian imaging is crucial for diagnosis of PCOS. Since PCOS by definition is a syndrome, the presence of polycystic ovaries alone is insufficient for the diagnosis since they are not always associated with it. With the introduction of 3D ultrasound accurate evaluation of ovarian structure and stroma has become possible.

Hyperdense stroma and stromal abundance is a known feature of PCOS. Stromal abundance can present as increased echogenicity since it is densely packed, having raised stromal area and increased stromal volume. Those 
having long standing PCOS and an ovulation have denser stroma. Stromal area is calculated on 3D ultrasound using calipers in median longitudinal ovarian section (Figure 1).

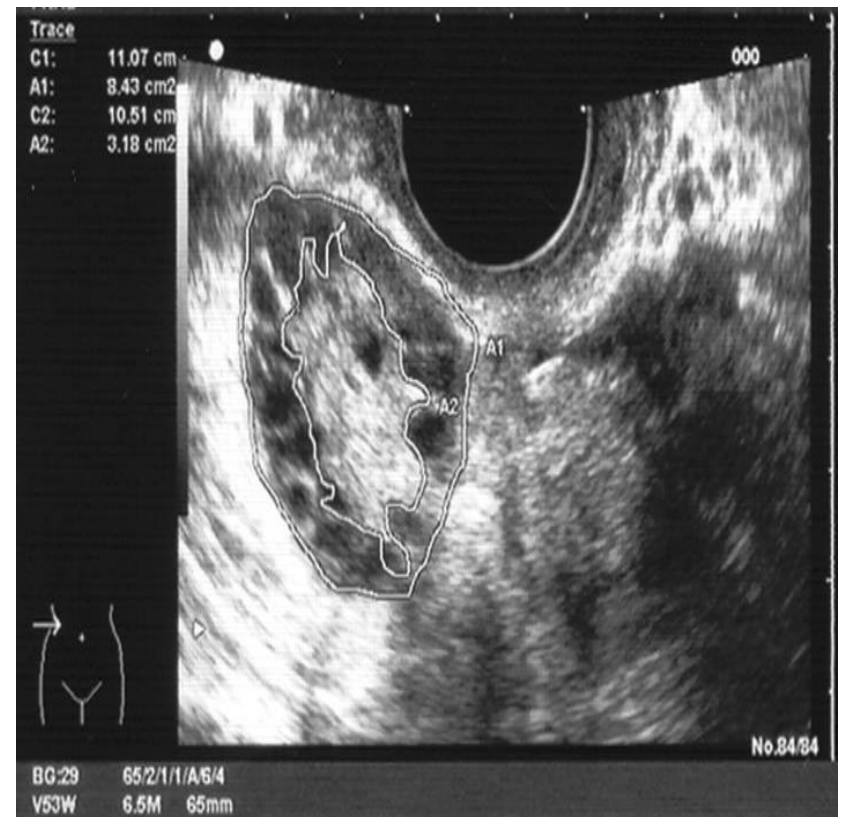

Figure 1: Method of obtaining median ovarian section with outlined ovarian and a stroma area $\mathrm{A1}$ is the total area and $\mathrm{A} 2$ is the stroma area.

Though ovarian volume is routinely used in the diagnosis of PCOS but it is the stromal area and the stromal volume that corresponds to the histological features of prominent theca cell hyperplasia that corresponds to the clinical features of this syndrome. In our study, it was observed that stromal area was significantly higher in the PCOS group $1.91 \pm 0.05 \mathrm{~cm}^{2}$ versus $1.44 \pm 0.59 \mathrm{~cm}^{2}$ in control group. Furthermore these results were consistent with the observations of Fulghesu AM et al in 2007 where stromal area was found $1.90 \pm 0.07 \mathrm{~cm}^{2}$ in cases and $1.5 \pm 0.001$ $\mathrm{cm}^{2}$ in controls. ${ }^{10}$ Similar results were demonstrated by Loverro et al in $2010 .^{9}$

In our study total ovarian area identified as $6.69 \pm 1.52$ $\mathrm{cm}^{2}$ versus $6.96 \pm 1.01 \mathrm{~cm}^{2}$ which were not statistically significant and findings were consistent with the observations by Fulghesu AM et al and Loverro et al. ${ }^{7,9}$

Though various studies have emphasized the role of ovarian stromal measurement but it is still in the research field.

In our study stroma to area ratio(S/A) was obtained as follows-outlining the peripheral profile of the stroma with caliper and the total ovarian area by outlining the external limits of the ovary in the maximum median plane section as obtained by Fulghesu AM et al. ${ }^{7}$ The ratio was observed to range from 0.14 to 0.38 which was significantly higher in cases $0.28 \pm 0.05$ versus $0.20 \pm 0.005$ in controls.
Dehydroepiandrosterone Sulphate is a male hormone which is secreted by adrenal glands in all females, though amounts are increased in PCOS as a part and parcel of disrupted physiology. It acts as a potent precursor for androgen synthesis. We found a positive correlation of DHEAS with S/A ratio $(r=0.565, \mathrm{p}<0.0001)$ as oppose to the study conducted by Fulghesu AM et al. ${ }^{7}$ They observed it to best correlate with the Testosterone and Androstenedione levels and further confirmed S/A ratio to be the best indicator of hyperandrogenism. We demonstrated a positive and significant correlation between testosterone and S/A ratio $(\mathrm{r}=0.27, \mathrm{p}=0.044)$ as observed by Loverro et al and Qiu Y et al. ${ }^{9,10}$

Stromal echogenicity can be assessed subjectively on ultrasound but it is non-reproducible and prone for interobserver variation. We assessed the echogenicity in the manner as described by Pache et al by giving a score 1 (normal), 2 (moderately increased) and 3 (frankly increased) by comparing with myometrium. ${ }^{11}$ There was a statistically significant association of testosterone with score 1 and 3 with $\mathrm{p}<0.05$ whereas association with DHEAS and score 3 was significantly associated.

\section{CONCLUSION}

This study concludes that S/A ratio bears a positive and significant correlation with androgenic parameters studied and can be considered as best predictor of hyper androgenism. Similarly stroma echogenicity measured can act as a clue to the diagnosis of PCOS. By measuring S/A ratio and stromal echogenicity on ultrasound and their follow up during the course of treatment may have significant role in defining severity, progression or regression of disease.

\section{ACKNOWLWDGEMENTS}

Authors would like to acknowledge with great pleasure and deep sense of gratitude for invaluable help of their teachers, colleagues and family members. No words can adequately express the importance of their timely offered guidance and support.

\section{Funding: No funding sources}

Conflict of interest: None declared

Ethical approval: The study was approved by the Institutional Ethics Committee

\section{REFERENCES}

1. Stein IF, Leventhal ML. Amenorrhea associated with bilateral polycystic ovaries. Am J Obstet Gynecol. 1935;29:181-91.

2. Nelson-Degrave VL, Wickenheisser JK, Hendricks KL, Asano $\mathrm{T}$, Fujishiro $\mathrm{M}$ et al. Alterations in mitogen-activated protein kinase and extracellular regulated kinase signaling in theca cells contribute to excessive androgen production in polycystic ovary syndrome. Mol Endocrinol. 2005;19:379-90. 
3. Nelson VL, Legro RS, Strauss JF $3^{\text {rd }}$, McAllister JM. Augmented androgen production is a stable steroidogenic phenotype of propagated theca cells from polycystic ovaries. Mol Endocrinol. 1995;13: 946-57.

4. Gilling-Smith C, Story H, Rogers V, Franks S. Evidence for a primary abnormality of thecal cell steroidogenesis in the polycystic ovary syndrome. Clin Endocrinol (Oxf). 1997;47:93-9.

5. Robert WA, Manfreddy R, Sheri C,Enrico C. Lipid levels in Polycystic Ovary Syndronme: systematic review and meta-analysis. Fertility and Sterility. 2011;95:1073-8.

6. Dewailly D, Robert Y, Helin I, Ardaens Y, ThomasDesrousseaux P, Lemaitre L et al. Ovarian Stromal Hypertrophy in Hyperandrogenic women. Clin Endorinol (oxf). 1994;41(5):557-62 .

7. Fulghesu AM, Angioni S, Frau E, Belosi C, Apa R, Mioni R, Xamin N et al. Ultrasonography in PCOSmeasuring Ovarian Stroma and Relationship with Circulating Androgens. Human Reproduction. 2007; 22(9):2501-8.

8. Lam P, Fenning RN, Cheung L, Haines C. Threedimensional ultrasound features of the polycystic ovary in Chinese women. Ultrasound Obstet Gynecol . 2009;34:196-200.

9. Loverro G, Pergola G, Naro ED, Tartagni M, Lavopa C, Caringella AM. Predictive value of ovarian stroma measurement for cardiovascular risk in polycystic ovary syndrome: a case control study. J Ovarian Reserve . 2010;3:25-9.

10. Qiu Y, Liu J, Zhou YF, Gui WW, Liu SW, Wang FL et al. Ultrasound criterion for the diagnosis of polycystic ovary syndrome: ovarian stroma/total area ratio. Zhonghua Fu Chan Ke Za Zhi.2004:39(9):5957.

11. Pache TD, Hop WC, Wladimiroff JW, Schipper J and Fauser BCJM. Transvaginal sonography and abnormal ovarian appearance in menstrual cycle disturbances. Ultrasound Med Biol. 1991;17:589-93.

Cite this article as: Gupta P, Gaikwad H.

Correlation of severity of hyperandrogenism with ovarian stroma to area ratio and stromal echogenicity in polycystic ovary syndrome patients. Int $\mathrm{J}$ Reprod Contracept Obstet Gynecol 2016;5:116-20. 